\title{
POTENCIAL DOS PROBIÓTICOS PARA O USO NA AQUICULTURA
}

Bruno Bezerra VIEIRA ${ }^{1}$

Erlon Lopes PEREIRA ${ }^{2}$

\begin{abstract}
${ }^{1}$ Universidade Federal de Viçosa. Departamento de Química da Universidade Federal de Viçosa. brunovieira08@yahoo.com.br

${ }^{2}$ Universidade Federal de Viçosa/Professor do curso de Engenharia Química e Bacharel/Licenciatura em Química do Departamento de Química da Universidade Federal de Viçosa. erlonlopes@gmail.com
\end{abstract}

Recebido em: 12/06/2016 - Aprovado em: 16/12/2016 - Disponibilizado em: 18/12/2016

\section{RESUMO}

Diversas pesquisas mostram os efeitos positivos da utilização da probióticos em humanos, suínos, ruminantes, cães e peixes. O principal efeito do uso de probióticos na alimentação é o estímulo do sistema imunológico dos animais. O objetivo deste trabalho foi de apresentar uma revisão bibliográfica, apresentando os conceitos relacionados ao uso de probióticos na aquicultura, que é o setor de alimentos que mais cresceu nos últimos 50 anos no mundo. Dentro do setor da aquicultura o foco foi analisar os efeitos da utilização do Bacillussp. na produção de Ciprinídeos (carpas), visto que esta família de peixes é a mais produzida comercialmente, além de apresentar reatores de produção destes microrganismos probióticos.

Palavras-chave: Carpas. Bacillussp probióticos. Aquicultura.

\section{Potential probiotics for use in aquaculture}

\begin{abstract}
:
Several researches show the positive effects of using probiotics in humans, pigs, ruminants, dogs and fishes. The major effect of using probiotics in food is the stimulation of the immune system of animals. Therefore, the objective of this study was to present a literature review of concepts related to the use of probiotics on agriculture, which is the world industry that has grown the most in the last 50 years. Within the agricultural sector the focus was to analyze the effects of using Baccilus sp. in the production of Ciprinídeos (carps), since this fish family is the most commercially, as well as present the reactors applied in production of probiotic microorganisms.
\end{abstract}

Keywords: Carps. Bacillus sp.probiotics. Aquaculture.

\section{Introdução}

O departamento de assuntos econômicos e sociais da Organização das Nações Unidas (ONU), divulgou um relatório de perspectivas de crescimento da população mundial. Neste documento, a ONU mencionou que a população mundial em 2015 era de aproximadamente 7 bilhões de pessoas e fez uma projeção de crescimento populacional onde estimou-se que, em 2050, o planeta será habitado por cerca de 9 bilhões de indivíduos. A
Organização Mundial da Saúde (OMS) em seu relatório anual sobre estatísticas globais de saúde apontou que a expectativa de vida aumentou 5 anos entre os anos de 2000 e 2015, período de maior aumento desde a década de 60 . A ONU fez uma projeção para o ano de 2045, onde a expectativa de vida global atingirá os 76 anos.

O crescimento sinérgico da população e da expectativa de vida implicam diretamente em questões de saúde e ao envelhecimento, na urbanização acelerada, na demanda por serviços 
básicos de saneamento e no abastecimento de alimentos cuja produção deve crescer no mesmo ritmo da população mundial. Nesta conjuntura demográfica, há uma busca constante pela prevenção de doenças graves, o que resulta na adoção de um estilo de vida mais saudável, e pelo aumento da produção de alimentos para atendimento da demanda crescente.

A Organização das Nações Unidas para Alimentação e Agricultura (FAO, na sigla em inglês) projetou que, para que a demanda de alimentos, em 2050, seja atingida é necessário que os países invistam anualmente US\$ 44 bilhões na produção e distribuição de alimentos, sendo que este recurso é cinco vezes maior do que os US\$ 7,9 bilhões que são investidos atualmente. Com este aporte orçamentário, a produção de alimentos deverá crescer aproximadamente $60 \%$, sendo este o valor considerado o necessário para o atendimento das necessidades alimentares em 2050. O mesmo órgão ainda enfoca que esta produção deve estar aliada ao desenvolvimento tecnológico que irá permitir o aumento da efetividade do cultivo e não de expansão da área plantada para que se possa garantir a sustentabilidade do sistema de produção.

Este cenário desafia a sociedade a desenvolver novas tecnologias capazes de suprir estas necessidades de melhoria de saúde e aumento da produtividade de alimentos. Os alimentos funcionais, especialmente os probióticos, prebióticos e simbióticos, despertaram grande interesse, tendo em vista que melhoram o estado de saúde dos indivíduos que os utilizam regularmente, além de aumentar a produtividade animal (SBRT, 2014).

$\mathrm{O}$ termo probiótico deriva do grego e significa "pró-vida", sendo o antônimo de antibiótico que significa "contra-vida". A definição, internacionalmente aceita, para o termo "Probióticos", foi divulgada em 2001 pela Organização Mundial da Saúde (OMS/WHO) juntamente com a Organização das Nações Unidas para Agricultura e Alimentação (FAO). Estas instituições conceituam probióticos como organismos vivos que, quando administrados em quantidades adequadas, conferem benefício à saúde do hospedeiro(FAO, 2001).Os termo prebióticos e simbióticos são definidos nas Diretrizes Mundiais da Organização Mundial de Gastroenterologia. Destas definições seguem que os Prebióticos são ingredientes, seletivamente fermentados, que permitem modificações específicas na composição e/ou atividade da microbiota intestinal, conferindo assim benefícios à saúde do hospedeiro. Já os simbióticos são produtos que contêm tanto probióticos como prebióticos (OMG, 2016).

De acordo com a FAO (2014) a aquicultura é o setor de produção de alimentos que mais cresce no mundo, com uma taxa de crescimento média anual de 8,9\% desde 1970. Para o mesmo período, a taxa de crescimento da pesca de captura foi de apenas 1,2\% e, para os sistemas terrestres de produção de carne o crescimento foi de 2,8\%. Em 2012, a produção foi de 66,63 milhões de toneladas, sendo o setor 
alimentício que mais cresceu nos últimos 50 anos. De maneira global, o Cyprinus carpio (carpa comum) se configura como o grupo mais importante da aquicultura, contribuindo com mais de $72 \%$ da produção em água doce (KUHLWEIN et al., 2014). O crescimento da produção de outras espécies de pescados segue a mesma tendência de crescimento da carpa comum (FAO, 2016).

De acordo com dados do Ministério da Pesca e da Aquicultura, o Brasil se destaca no potencial de desenvolvimento da produção de pescados. Este destaque deve-se ao fato do país ser constituído por $8400 \mathrm{~km}$ de costa marítima e, aproximadamente $12 \%$ de toda a água doce do planeta, o que corresponde a 5,5 milhões de hectares de reservatórios. O clima também é um fator extremamente favorável para o crescimento de organismos cultivados. Além disso, o aumento da demanda de pescados no mercado, aliado à disponibilidade de mão de obra e terra baratas contribuem de forma significativa para o desenvolvimento acelerado da aquicultura no país (EMBRAPA, 2015).

A aquicultura utiliza-se dos recursos hídricos para o seu desenvolvimento. Os animais aquáticos possuem uma relação muito mais forte com o ambiente que vivem do que os animais terrestres. Organismos potencialmente patogênicos são capazes de se desenvolverem no ambiente dos animais aquáticos, independente do hospedeiro. O desenvolvimento de doenças ou quaisquer desequilíbrios na produção podem levar a deteriorações das condições ambientais e graves perdas econômicas para o setor. O uso de antibióticos nos sistemas aquáticos de produção de pescados tem sido a estratégia usada para o controle de doenças, melhoria do crescimento e eficiência da conversão alimentar, durante as últimas duas décadas. Todavia, pesquisas têm mostrado a disseminação da resistência a estes antibióticos pelos organismos patogênicos. Além disso, existe o risco da transmissão destas bactérias resistentes do ambiente aquático para os humanos que ingerem o peixe contaminado. Diante deste cenário, existe uma necessidade do desenvolvimento de nova suplementação dietética que seja promotora da saúde e contribua para a maximização da produção com foco na sustentabilidade dos ambientes aquáticos (PANDIYAN et al., 2013).

Pandiyan et al. (2013) destacam que a nutrição com alimentos probióticos, prebióticos ou mesmo simbióticos é uma prática que pode exercer um papel importante na aquicultura, sendo eficazes na prevenção de doenças e tratamento de um amplo espectro de microrganismos patogênicos. Isto porque estes alimentos são capazes de estimular o sistema imunológico dos animais através da incitação ao desenvolvimento dos microrganismos benéficos e supressão do crescimento dos patogênicos.

A aquicultura sendo o setor produtivo de alimentos que mais cresce em nível global, o que estimula o interesse dos pesquisadores em desenvolver dietas e processos de cultivo que 
melhorem a eficiência do processo de conversão alimentar e ganho de peso dos peixes.Visto o exposto este trabalho objetivou apresentar uma revisão sobre o uso de probióticos na aquicultura destacando seu mecanismo de ação em peixes, o uso destes em carpas além dos processos biotecnologicos utilizados na produção de probióticos para aquicultura.

\section{Referencial teórico}

\subsection{Mecanismo de ação e benefícios da utilização}

Segundo a OMS e FAO (2006) os probióticos, prebióticos e simbióticos possuem ação de estímulo do crescimento de bactérias anaeróbias benéficas e supressão do crescimento das bactérias patogênicas. Quando o probiótico é administrado de forma regular, ocorre uma modificação do ecossistema intestinal. Os microrganismos probióticos aderem à parede intestinal promovendo uma barreira imunológica, competindo com os microrganismos patogênicos por sítios de adesão e minimizando a ação destes. A supressão do desenvolvimento de bactérias patogênicas é considerado um mecanismo nãoimune, uma vez que os probióticos são capazes de produzir compostos que inibem o crescimento ou até mesmo que provoque a morte das mesmas.

Alguns benefícios da utilização de probióticos em humanos podem ser descritos como: indução do sistema imunológico
(DWIVEDI et al., 2016), para tratamento de doenças dermatológicas

(FUCHSTARLOVSKY;

MARQUEZ-BARBA; SRIRAM, 2016), no tratamento de diarreia aguda (ZUPPA et al., 2016), na redução da diarreia associada a antibióticos (OUWEHAND; TENNILÄ, 2016), no controle da obesidade (ROUXINOL-DIAS et al., 2016), na prevenção de infecções virais no sistema respiratório (AHANCHIAN; JAFARI, 2016),nas disfunções intestinais como constipação (HOD; RINGEL, 2016), e na prevenção de câncer colorretal (AMBALAM et al., 2016).

Trabalhos científicos recentes sobre as propriedades e funcionalidade de microrganismos vivos na produção de suínos (ZIMMERMANN et al., 2016, VLASOVA et al., 2016, KUMAR et al., 2014, LAN; KOO; KIM, 2016, XU et al., 2016), ruminantes (STOVER; WATSON; COLLIER, 2016, ELLIS et al., 2016, VOHRA; SYAL; MADAN, 2016), peixes (MUNIR et al., 2016, CEREZUELA et al., 2016, ADEOYE et al., 2016), cães (GONZÁLEZ-FORTE; BRUNO; MARTINO, 2014, STROMPFOVÁ et al., 2014, GRZEŚKOWIAK et al., 2015) etc... têm sugerido que os probióticos desempenham um papel importante na função imunológica, funções digestivas e respiratórias, tendo ainda efeito significativo sobre o alívio de doenças infecciosas. Por isso, a indústria de alimentos tem investido bastante no setor de probióticos. A diversidade de produtos, tanto em número 
quanto em tipos, tem crescido significativamente.

\subsection{Bactérias ácido-láticas}

O grupo das bactérias ácido-láticas (BAL) é o grupo mais utilizado como microrganismo probiótico. As espécies dos gêneros Lactobacillus e Bifidobactérium são os representantes utilizados com maior frequência como aditivos alimentares. Porém, alguns fungos, como o Saccharomyces cerevisiae, espécies do gênero Bacillus e Escherichia também podem ser utilizadas como probióticos (NOGUEIRA, 2011).

O termo bactérias ácido-láticas (BAL) se refere a um grupo diverso de bactérias. $\mathrm{Na}$ descrição de uma BAL típica, salvo algumas exceções, incluem-se como características destes microrganismos: Gram Positivos e catalase negativos (EMBRAPA 2011) , fastidiosos, não esporulados, destituído de citocromo, ácido tolerantes, geralmente sem mobilidade e anaeróbios facultativos (SAVIJOKI; INGMER; VARMANEN, 2006).A característica essencial do metabolismos das LAB é a fermentação eficiente de carboidratos, associada à fosforilação à nível de substrato. (PEYER; ZANNINI; ARENDT, 2016).

A fermentação deve ser entendida como um fenômeno biológico de transformação de compostos orgânicos complexos, geralmente açúcares, em compostos orgânicos mais simples, ocorrendo a liberação de gás carbônico e energia. É utilizada mundialmente para a preservação de uma série de produtos agrícolas minimamente processados (cereais, raízes, tubérculos, frutas e hortaliças, leite, carne e peixe).A produção de ácidos orgânicos pelas BAL diminui o $\mathrm{pH}$ e torna o meio seletivo contra outros microrganismos menos ácidotolerantes (ADAMS, 2014).

\subsection{Antibióticos $x$ Probióticos}

Os antibióticos são definidos como substâncias químicas que têm a capacidade de, em solução diluída, para eliminar ou inibir o crescimento de microrganismos (FERNANDES; MARTENS, 2016).

Em meados de 1928 Alexander Fleming, um bacteriologista no St. Mary, em Londres, deu início à era de ouro dos antibióticos com a descoberta da penicilina. Esta descoberta revolucionou o campo dos medicamentos, propiciando uma diminuição da taxa de mortalidade, com consequente aumento da expectativa de vida em todo o mundo (SINGH et al., 2011).

Singh et al. (2011) esclarecem que o organismo humano deve ser entendido como um ecossistema, onde existe uma perfeita simbiose entre os microrganismos do trato digestivo e o próprio corpo.Quando se utiliza um antibiótico, além de matar as bactérias patogênicas, mata-se também as bactérias benéficas, desequilibrando o ecossistema. $\mathrm{O}$ uso indiscriminado e incorreto de antibióticos pode selecionar microrganismos 
resistentes que podem ocasionar superinfecções que se tornam cada dia mais difíceis de tratar.

O mecanismo de ação do uso regular de probióticos é estimular o crescimento de bactérias benéficas e suprimir o crescimento das bactérias patogênicas, além de melhorar o sistema imunológico, o que mantém o equilibrio do corpo. Os probióticos ainda são importantes na recuperação da microbiota intestinal após a utilização prolongada de antibióticos.

Diante destes fatos, a utilização dos microrganismos probióticos deve ser encarada como uma medida de saúde preventiva humana e animal, que estimula o sistema de defesa, sendo que o uso de antibióticos é uma medida corretiva que deve ser evitada, uma vez que, produz efeitos de desequilíbrio do ecossistema corporal.

\section{Probióticos na aquicultura}

\subsection{Efeitos dos probióticos na saúde animal}

Torres (2014), em seus trabalhos com efeitos dos probióticos, fizeram um delineamento dos principais benefícios da utilização dos probióticos nos animais de forma geral, o que pode ser observado na Figura 1.

A Figura 1 mostra que a utilização dos alimentos probióticos e prebióticos na aquicultura contribui de forma significativa para o controle de doenças, além de melhorar a conversão de alimentos em peso animal. A contribuição mais significativa destes tipos de alimentos é o estímulo do sistema imunológico dos animais.

Figura 1 - Efeito das bactérias não-patogênicas no trato intestinal

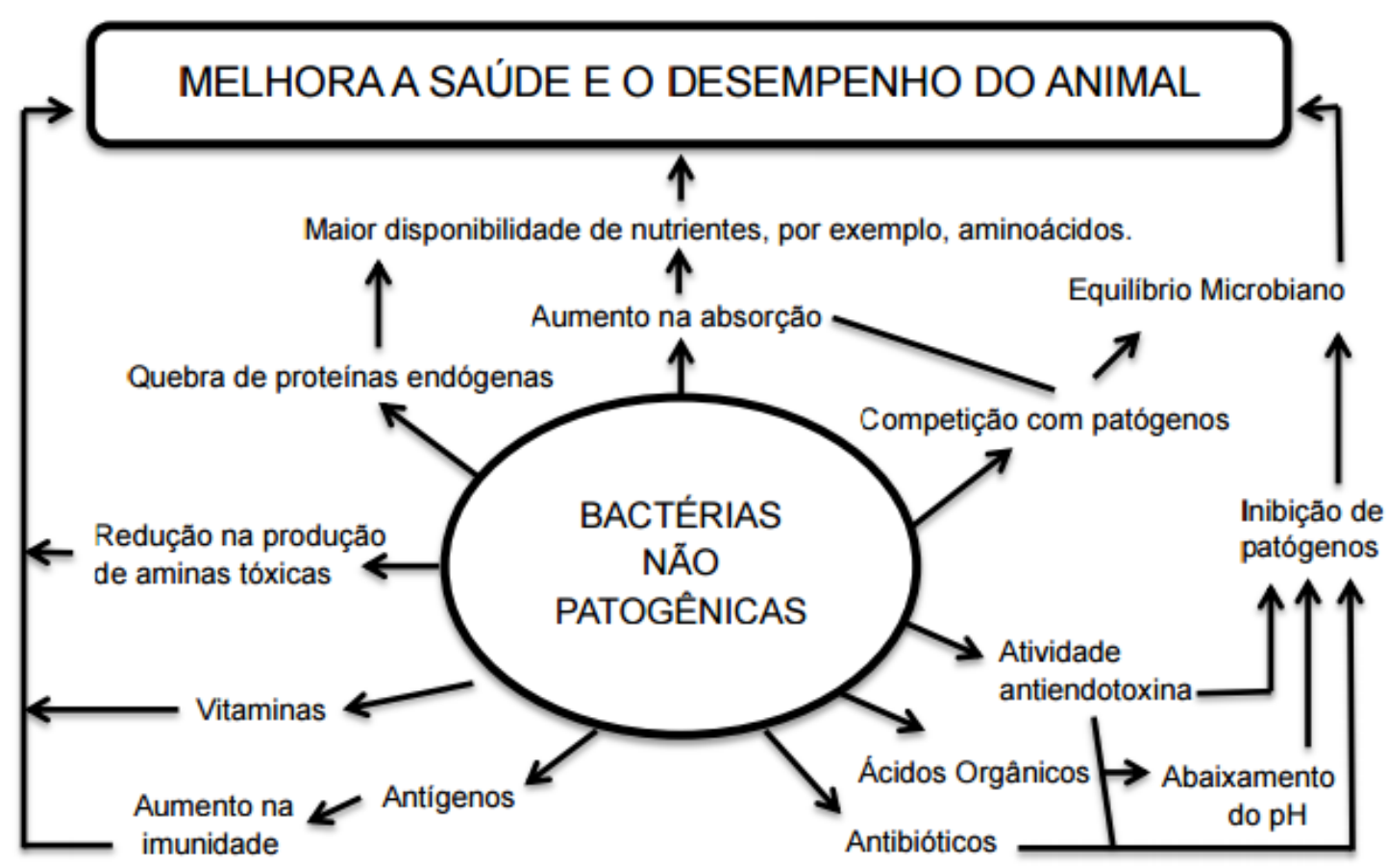

Fonte: Torres (2014) 


\subsection{Probióticos na produção de carpas}

A FAO (2016) descreveu que os Ciprinídeos (família Cyprinidae), ou carpas, são criados há mais de 2000 anos na China, em tanques de armazenamento, onde os alevinos que deram origem à criação foram retirados de rios. A carpa era um alimento de luxo no período romano meio e final, e foi consumido durante o jejum na Idade Média. Nesta época as carpas eram criadas sob a forma de monocultura. Além disso, os maiores indivíduos eram selecionados e colocados em novos tanques, provocando uma seleção intencional, sendo este o primeiro passo para a domesticação efetiva destas espécies de peixe. Existem cerca de 30 a 35 espécies de carpas comuns domesticados na Europa. As carpas são peixes resistentes a condições adversas, podendo sobreviver a períodos frios de inverno, baixa concentração de oxigênio $\left(0,3\right.$ a $\left.0,5 \mathrm{mg} \mathrm{L}^{-1}\right)$ ou até mesmo a supersaturação do gás. São animais onívoros que se alimentam basicamente de insetos aquáticos, larvas de insetos, vermes, moluscos e zooplâncton. $\mathrm{O}$ consumo de zooplâncton é dominante em viveiros de peixes onde a densidade populacional é alta. Além disso, a carpa consome os talos, folhas e sementes de plantas aquáticas e terrestres. $\mathrm{O}$ crescimento diário da carpa geralmente é de 2 a 4 por cento de peso corporal. Carpas pode atingir 0,6 a $1,0 \mathrm{~kg}$ de peso corporal dentro de uma estação de criação dentro de viveiros de áreas subtropicais / tropical. O crescimento é muito mais lento em zona temperada, onde o peixe pode chegar ao 1-2 $\mathrm{kg}$ de peso corporal após 2 a 4 estações de criação.

De acordo com DAWOOD e KOSHIO (2015) a resposta imunológica de peixes é a reação contra agentes estranhos como bactérias, fungos, vírus, protozoários, parasitas multicelulares, macromoléculas como proteínas e polissacarídeos e outros agentes estressores ligados ao ambiente aquático que não possuem consequências patológicas. A resposta imune dos peixes é, muitas vezes, modulada por fatores externos relacionados com o ambiente em que vivem. Fatores ambientais como, temperatura, salinidade, fotoperíodo são associados aos fatores de estado fisiológico como nutrição, idade, ciclo reprodutivo, equilíbrio hormonal e estresse para a melhoria do estado de saúde dos animais. A utilização de imunoestimulantes, principalmente os advindos de fontes naturais, é uma prática que vêm sendo aplicada com sucesso na aquicultura no sentido de redução das doenças infecciosas e estresse dos animais.

A utilização dos probióticos na produção de pescados se dá por meio da aplicação direta nos tanques ou através da adição à ração tendo papel importante na prevenção de doenças, embora efeitos nutricionais muitas vezes são associados a este incremento, principalmente no caso dos organismos filtradores (DECAMP et al., 2006).

Assim, como na maioria das aplicações, na aquicultura as bactérias ácido-lácticas são o grupo de microrganismos mais utilizados como 
probióticos. Neste grupo se destacam as bactérias do gênero Lactobacillus e Carnobacterium. Ainda possuem destaque as bactérias dos gêneros Vibrio, Bacillus e Pseudomonas, embora outros gêneros e espécies também são utilizados (JESUS, 2014).

Verschuere (2000) e Reid (2016) destacam que os principais modos de ação dos probióticos na aquicultura são: produção de compostos inibitórios; competição por produtos químicos ou energia disponíveis, competição por sítios de adesão, melhoria da resposta imune, melhoria da qualidade da água, interação com fitoplâncton fonte de macro e micronutrientes; e contribuição para a digestão enzimática.

\subsubsection{Caracterização de microrganismos como probióticos}

Algumas características específicas são desejáveis que os microrganismos possuam para serem classificados como probióticos. São características que variam de acordo com o animal que utilizam os probióticos, mas que de forma geral contribuem para a melhoria do estado de saúde dos mesmos. Alguns destes critérios são a resistência a antibióticos, a inibição de patógenos, produção de celulase, habilidade de esporulação e resistência ao calor, baixo $\mathrm{pH}$ e à bílis.

Guo et al. (2016), apresentaram um trabalho de identificação e isolamento de Bacillus subtilis do intestino de carpas capim (Ctenopharynodon
Idellus) e avaliaram o potencial de utilização desta bactéria como probiótico em aditivos alimentares utilizados na produção deste peixe.

Peixes saudáveis, com peso corporal de cerca de $1500 \mathrm{~g}$, foram anestesiados por imersão num tanque contendo metanossulfonato tricaina (MS-222). O trato digestivo foi dissecado, cortado em pedaços e, em seguida, homogeneizado. O conteúdo intestinal foi homogeneizado e distribuídos em placas de petri, para enfim serem incubados a $37^{\circ} \mathrm{C}$ por 24 horas. Após crescimento, utilizando-se da análise filogenética e da análise do DNA os autores conseguiram identificar e isolar o Bacillus subtilis (GUO et al., 2016).

\subsubsection{Inibição de Patógenos}

A inibição de microrganismos patogênicos é uma das características mais importantes dos probióticos, tendo em vista que agem na supressão do crescimento dos agentes responsáveis pelas doenças que afetam todo o desenvolvimento animal.

Guo et al. (2016) avaliaram a capacidade do Bacillus subtilis em inibir o crescimento de patógenos importantes. As bactérias patogênicas avaliadas foram Aeromonas hydrophila, Aeromonas punctata, Edwardsiella ictaluri, Aeromonas punctata $f$. intestinali, flurialis Vibrio, e Streptococcus agalactiae. $\mathrm{O}$ experimento consistiu de crescer estes microrganismos em placas que possuíam 3 poços. Dentro destes poços foi inserida uma 
solução de Bacillus subtilis. A capacidade de inibição do agente patogénico foi determinada de acordo com a o halo de inibição (diâmetro externo menos o diâmetro do poço). O Bacillus subtilis foi capaz de inibir todos os microrganismos patogênicos avaliados.

Flesch et al. (2014) mencionam que para certas doenças o antibiótico deve ser utilizado de forma sinergica com o probiotico. Por este motivo, para que o probiótico seja eficaz em seu mecanismo de ação, deve possuir resistencia a antibióticos utilizados na aquicultura para permitir esse uso conjunto.

\subsubsection{Resistência do probiótico a antibióticos}

Pinto et al. (2006), citam que, dentre propriedades requeridas para uma bactéria ser considerada como um potencial probiótico aquático, ela não deve apenas ser seguro para os peixes, mas também não abrigarem resistência adquirida e transferível aos antibióticos. No sentido de avaliar a resistência de Bacillus subtilis a alguns antibióticos, Guo et al. (2016) avaliaram a mínima concentração de inibição (MIC) ao antibióticos gentamicina, canamicina, estreptomicina, tetraciclina, eritromicina, cloranfenicol, ampicilina, vancomicina e clindamicina. MIC é a concentração mais baixa de antibiótico que inibe visível. O teste foi realizado de acordocom o método recomendado pela Comissão Nacional de ClínicaLaboratory Standards (NCCLS). Uma cepa bacteriana é considerada resistente a um antibiótico quando a sua MIC é superior a um valor de corte estabelecido pela Autoridade Europeia para a Segurança dos Alimentos. As cepas de Bacillus subtilis foram resistentes à estreptomicina, ampicilina e clindamicina.

\subsubsection{Produção de Celulase}

Através da análise dos trabalhos desenvolvidos por Guo et al. (2016) foi possivel perceber que a alta produção de celulase é desejável em um microrganismo potencialmente probiótico. Partindo do conhecimento que as rações são alimentos ricos em fibras celulósicas alimentares , a celulase no intestino melhora a utilização dos alimentos, aumentando a conversão alimentar e ganho de peso dos animais.

Auger et al. (2009) avaliaram a capacidade doBacillus subtilisem produzir a celulase. O método consistiu basicamente de inoculação do microrganismo numa placa de petri com ágar que continha a Carboximetilcelulose (CMC). A atividade da celulase foi avaliada diante do raio de hidrólise da CMC, descontando o raio da colônia. A região onde ocorria a degradação da CMC pela celulase era descolorida, ficando transparente. Em todos os testes realizados, alta atividade da celulase era registrada.

\subsubsection{Habilidade de esporulação}

A capacidade de esporulação é interessante para o uso do probiótico como aditivo alimentar. Isto se deve ao fato da forma 
esporulada das bactérias serem mais resistentes que a forma vegetativa, favorecendo a sobrevivência destas às condições adversa do sistema digestivo dos animais (GUO et al, 2016).

Cepas de Bacillus subtilis foram inoculadas e incubadas a $37^{\circ} \mathrm{C}$ pelos pesquisadores Guo et al. (2016). Após 24, 48 e 72 horas, foi realizada a contagem celular, com auxílio do microscópio (GFM-580, Nicon) e determinada a porcentagem de esporos em relação a células vegetativas. Passadas as 72 horas de incubação, 2 das 4 cepas atingiram $100 \%$ de esporulação. Umas das cepas atingiu $90 \%$ de esporulação e a última apenas $65 \%$.

\subsubsection{Resistências ao calor, $\mathrm{pH}$ baixo, e bílis}

A resistência às condições gástricas e à bile é a característica mais importante de um probiótico, visto que este necessita chegar ao intestino delgado viável para que ocorra a colonização deste e os efeitos desta adesão e crescimento ao intestino de fato aconteçam (FADDA et al., 2017).

Guo et al. (2016) inocularam e incubaram cepas de Bacillus subtilis a $37^{\circ} \mathrm{C}$ por 72 e 96 horas. Todas as células vegetativas foram mortas por tratamento com lisozima. Os esporos foram submetidos a 3 tratamentos diferentes.

Primeiramente os esporos sofreram um tratamento térmico onde foram aquecidos a 80 , 90 e $100^{\circ} \mathrm{C}$ por 2,5 e 10 minutos respectivamente. As taxas de sobrevivência das cepas eram próximas a $100 \%$ até o tratamento de $100^{\circ} \mathrm{C}$ por 5 minutos. Para os ensaios de $100^{\circ} \mathrm{C}$ e 10 minutos, a taxa de sobrevivência caía para aproximadamente $60 \%$.

$\mathrm{O}$ tratamento que avaliou a resistência às condições gástricas consistiu de expor os esporos aos pH's 1, 2 e 3 por cerca de 2 horas e à bile fresca de carpa do limo em concentrações de $2,4,6,8$ e $10 \%$ a $37^{\circ} \mathrm{C}$. Foram contabilizadas as bactérias sobreviventes. Em relação à concentração biliar não houve diferenças significativas de sobrevivência entre os tratamentos. Em relação ao pH observou-se alta sobrevivência dos esporos nos tratamentos avaliados, apesar da sobrevivência diminuir com a diminuição do $\mathrm{pH}$.

\subsection{Produção de microrganismos probióticos}

De maneira geral, o processo de cultivo de microrganismos se inicia com o cultivo do microrganismos em laboratório em pequena escala, em meio semi-sólido ou líquido nas estufas de crescimento. A seguir, ocorre a repicagem do inóculo, que consiste da transferência de uma parcela dos microrganismos para um meio nutritivo para a reprodução dos mesmos. Esta repicagem deve ser realizada em frascos com tamanhos crescentes para o aumento de escala da produção dos microrganismos. Esta operação deve ser realizada até que seja produzido o 
volume adequado para a inoculação nos reatores biológicos fermentativos, que são os mais utilizados para o cultivo de microrganismos. Nos reatores biológicos ocorre a inoculação dos microrganismos em um meio de cultura onde ocorrereá o cultivo dos mesmos. Assim que o regime estacionário de crescimento for atingido, o cultivo contendo os microrganismos e os nutrientes não consumidos são encaminhados para as etapas de concentração e secagem da biomassa. A Figura 2 representa um esquema do processo de produção de microrganismos, incluindo os probióticos.

Figura 2- Processo geral de produção de microrganismos probióticos

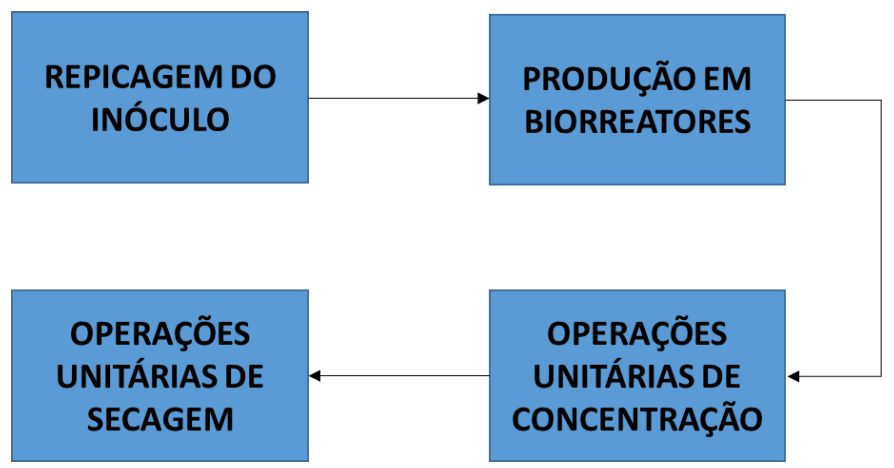

Fonte: Autoria própria

Os processos fermentativos, que ocorrem nos reatores biológicos, são importantes em diversos setores como na indústria farmacêutica, indústria química e na agricultura. A fermentação é destaque na indústria de alimentos, onde produtos como queijos, iogurtes, pães, carnes, vinagres, enzimas e diversos outros são obtidos através deste processo biológico.

Segundo a Embrapa (2016) os processos fermentativos estes podem ser classificados, primariamente, em dois tipos: a fermentação em estado semi-sólido (FSS) e fermentação submersa (FS).

A fermentação em estado semi-sólido consiste de uma fermentação onde o substrato está no estado sólido, praticamente em ausência de água livre, porém, com umidade suficiente para o crescimento e metabolismo microbianos
(ZANCHETTA, 2012). Esta técnica reproduz procedimentos naturais como a ensilagem e a compostagem, onde fungos filamentosos crescem sob a biomassa, utilizando-se da excreção de enzimas para degradá-la e, assim, utilizar seus nutrientes para a própria sobrevivência. (SINGHANIA et al., 2009).

A fermentação submersa consiste na utilização de um meio de cultura onde os nutrientes se encontram em meio aquoso, dissolvidos ou em suspensão. É o método de fermentação mais utilizado nas aplicações industriais, tendo em vista que o meio mais homogêneo, melhora a transferência de calor e massa e controle das variáveis de processo é mais eficiente (FAZENDA et al., 2008). A Figura 3 esquematiza os tipos de reatores associados a cada tipo de fermentação. 
Figura 3 - Tipos de reatores biológicos baseado em Silva (2010)

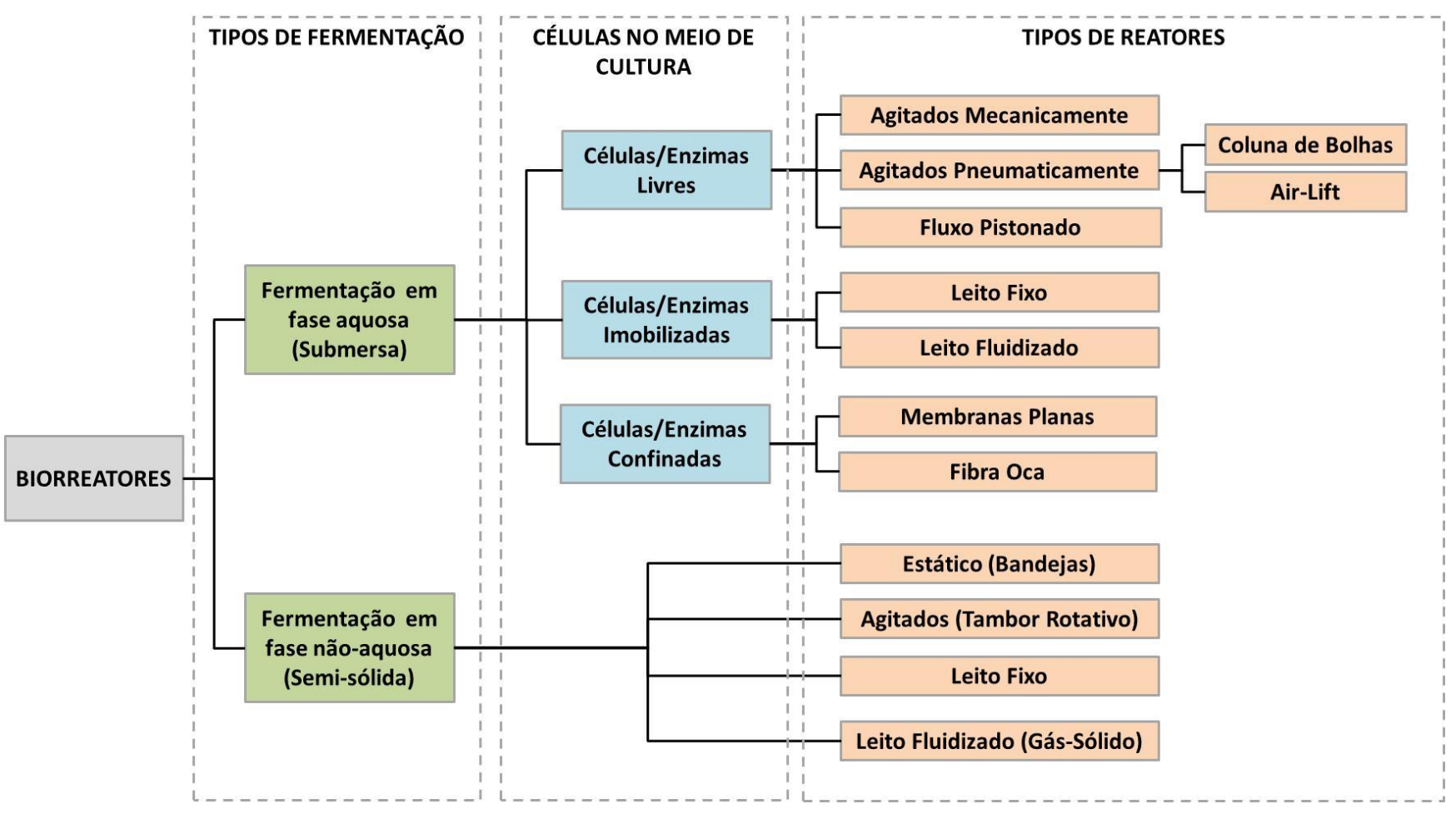

Fonte: Autoria própria

Silva (2010) realizou estudos de crescimento de Bacillus subtilis em biorreator de tanque agitado (STR), modelo Biostat B. (B. Braun Biotech International) de 5L. Para cada batelada experimental, um inóculo de densidade ótica igual a 1,0 $\pm 0,1$ foram adicionados ao meio de cultivo numa concentração de $4 \%(\mathrm{v} / \mathrm{v})$. Os cultivos foram conduzidos por 96 horas, sem controle de $\mathrm{pH}$ e com 2,5 L de meio de cultura.

Aguirre (2013) utilizou-se da fermentação semi-sólida em reatores tipo sacos plásticos para a produção de Bacillus sp. O meio de cultura foi preparado por misturas de farelo de trigo, arroz e de soja e como material de suporte inerte foi usada a casca de arroz. A granulometria do meio de cultura foi de 0,55 mm. O tamanho das partículas foi selecionado através do peneiramento em peneiras agitadas, onde foram coletadas as partículas retidas entre as peneiras MESH 48 e MESH 28. O meio foi enriquecido com a solução nutriente.

$\mathrm{Na}$ fermentação foram utilizados 30 gramas de meio de cultura cuja composição foi de $50 \%$ farelo de soja, $20 \%$ de farelo de arroz, $20 \%$ de farelo de trigo e $10 \%$ casca de arroz, com $50 \%$ de umidade. O meio foi esterilizado a $121^{\circ} \mathrm{C}$ por 15 minutos. Após a esterilização, o meio foi umidificado com solução $3 \mathrm{~S}$ e inoculado com $6 \mathrm{~mL}$ de solução de Bacillus sp, por meio de seringa hipodérmica em ambiente estéril. A fermentação ocorreu na temperatura de $30^{\circ} \mathrm{C}$ por 96 horas.

$$
\text { Segundo Voss (2013), os }
$$

biorreatores airlift são reatores pneumáticos que se diferenciam de outros reatores pneumáticos pelo tipo de fluxo de ar empregado. A circulação do líquido dentro dos reatores airlift ocorre devido ao design do reator. $O$ reator possui um tubo externo 
que liga o fundo à parte superior do reator, onde o líquido circula impulsionado pela injeção de ar. Os reatores do tipo airlift destacam-se dos demais tipos de reatores, visto que a injeção de ar promove a aeração e a circulação de meio em altas taxas, o que melhora a transferência de calor e massa, além de diminuir a tensão de cisalhamento nas células quando comparados aos reatores de agitação mecânica.
Voss (2013), utilizou um reator airlift de 5 L de volume útil, com controlador de temperatura, pH e vazão de ar. O biorreator foi esterilizado através da injeção direta de vapor em uma autoclave de 50 litros. $\mathrm{O}$ pH do reator foi mantido em 7 e a temperatura em $30^{\circ} \mathrm{C}$. $\mathrm{O}$ tempo de fermentação foi de 28 horas, mas o substrato foi praticamente esgotado em 24 horas, como pode ser observado nas curvas cinéticas apresentadas na Figura 4.

Figura 4 - Cinética de crescimento de Bacillus subtilis em reator airlift

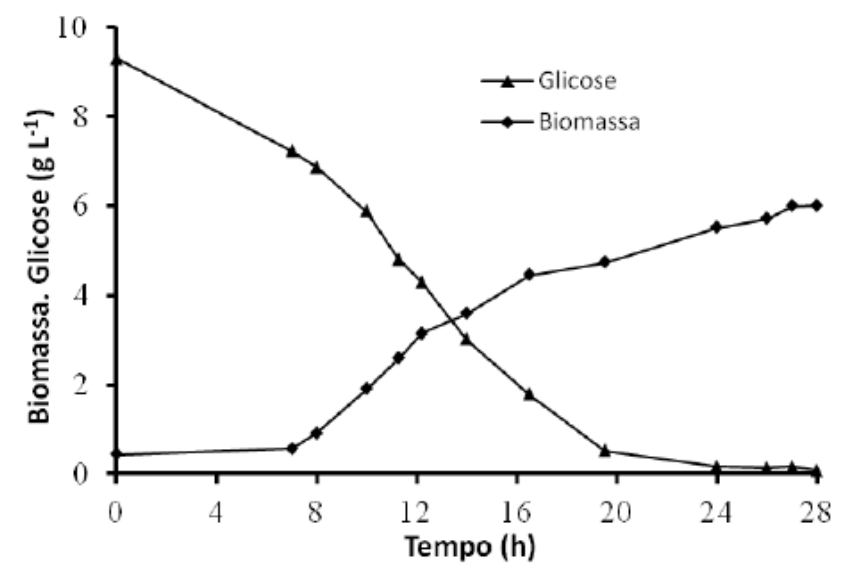

Fonte: Voss (2013)

Os reatores utilizados para a produção de Bacillus subtilis podem variar de acordo com a finalidade. Diante do exposto, a fermentação semi-sólida e os reatores tipo STR e airlift, que são reatores de fermentação submersa, são os mais utilizados para a produção do Bacillus subtilis.

As etapas subsequentes ao cultivo de microrganismos nos reatores biológicos são a concentração e secagem. Para que ocorra a concentração e secagem da biomassa são realizadas operações unitárias de separação sólido-líquido.

As operações unitárias de separaçãosólido, como a decantação, flotação, separação centrífuga e filtração possuem o objetivo de obtenção de um sólido com a mínima quantidade de água possível (PERRY, 2008).

A decantação e a flotação são processos de separação, onde a força da 
gravidade é utilizada para separar os sólidos da fase líquida. Uma corrente com a suspensão entra no equipamento de onde sai uma corrente concentrada de sólidos e outra corrente mais concentrada da fase líquida. Caso o sólido seja mais denso que a fase líquida, a decantação é utilizada. Quando os sólidos menos densos que a fase líquida a separação é realizada por flotação (NOUREDDIN et al., 2014).

A centrifugação é uma operação de separação gravitacional, onde o uso da força centrífuga aumenta muitas vezes a força da gravidade que atua sobre as partículas, diminuindo o tempo de residência no equipamento. É utilizada quando a diferença de densidade do sólido para a fase líquida dificulta sua separação por decantação ou flotação(DASSEY; THEEGALA, 2013).

A filtração é um método de separação onde a suspensão contendo o sólido é direcionada a um meio poroso cujos poros possuem dimensões menores do que os sólidos. Assim, este meio permite a passagem do líquido, mas retém os sólidos, havendo assim a separação dos dois componentes (MARBELIA et al., 2016).

Os separadores sólido-líquido apresentados possuem limitações e conseguem retirar a fase líquida da sólida até determinadas concentrações. Quando se deseja obter uma fração sólida com teores de líquidos muito baixos, a operação unitária da secagem se faz necessária.
A secagem é a remoção de um líquido presente em um sólido por meio da vaporização térmica, consistindo de um processo de transferência de calor em sinergia com a transferência de massa (POHNDORF et al., 2016).

Após a secagem ser realizada o produto contendo altas concentrações do microrganismo desejado pode ser utilizado em aplicações diretas ou indiretas aos animais que serão beneficiados pelo consumo do mesmo.

\section{Conclusão}

O uso de probióticos na aquicultura, como estratégia de suplementação dietética, ganha cada vez importância. A eficiência da conversão alimentar e do ganho de peso dos animais, aliado à diminuição da utilização de antibióticos são fatores importantíssimos da produção de peixes que são associados ao uso de probióticos. Dentro deste cenário, onde a aquicultura é o setor alimentício que mais cresce no mundo, a produção de carpas se destaca, uma vez que esta família de peixes é responsável por $72 \%$ do total de pescados produzidos.

Dentre os probióticos utilizados no crescimento dos ciprinídeos o Bacillus subtilis configura-se como uns dos microrganismos de maior potencial de utilização como probiótico devido às suas características de estímulo ao sistema imunológico e resistência 
aos antibióticos mais utilizados na aquicultura.

O processo de produção do microrganismo probiótico envolve o cultivo deste em escala laboratorial e seu respectivo aumento de escala para a utilização industrial em biorreatores. $\mathrm{Na}$ indústria ainda são realizadas operações de concentração e secagem da biomassa para a utilização como aditivo alimentar.

\section{Referências}

ADAMS, Martin R.. Acids and Fermentation. Food Safety

Management, [s.1.], p.467-479, 2014. Elsevier BV. http://dx.doi.org/10.1016/b9780-12-381504-0.00019-6.

ADEOYE, Ayodeji A. et al. Combined effects of exogenous enzymes and probiotic on Nile tilapia (Oreochromis niloticus) growth, intestinal morphology and microbiome. Aquaculture, [s.1.], v. 463, p.61-70, out. 2016. Elsevier BV. http://dx.doi.org/10.1016/j.aquaculture.2016.0 5.028 .

AGUIRRE, Cesar Augusto Piedrahita. Estudo da produção de iturina por bacillus subtilis, em fermentação semisólida utilizando como substrato farelos de soja, arroz, trigo e casca de arroz. 2013. $159 \mathrm{f}$. Tese (Doutorado) - Curso de Engenharia de Alimentos, Uicamp, Campinas, Sp, 2013.

AHANCHIAN, Hamid; JAFARI, Seyed Ali. Probiotics and Prebiotics for Prevention of Viral Respiratory Tract Infections.

Probiotics, Prebiotics, And

Synbiotics, [s.1.], p.575-583, 2016. Elsevier
BV. http://dx.doi.org/10.1016/b978-0-12802189-7.00042-3.

AMBALAM, Padma et al. Probiotics, prebiotics and colorectal cancer prevention. Best Practice \& Research Clinical Gastroenterology, [s.1.], v. 30, n. 1, p.119-131, fev. 2016. Elsevier BV. http://dx.doi.org/10.1016/j.bpg.2016.02.009.

AUGER, Sandrine et al. Biofilm Formation and Cell Surface Properties among Pathogenic and Nonpathogenic Strains of the Bacillus cereus Group. Applied And Environmental Microbiology, [s.i], v. 75, n. 20, p.6616-6618, 22 jul. 2009.

CEREZUELA, Rebeca et al. Enrichment of gilthead seabream (Sparusaurata L.) diet with palm fruit extracts and probiotics: Effects on skin mucosal immunity. Fish \& Shellfish Immunology, [s.1.], v. 49, p.100-109, fev. 2016. Elsevier BV. http://dx.doi.org/10.1016/j.fsi.2015.12.028.

DASSEY, Adam J.; THEEGALA, Chandra S.. Harvesting economics and strategies using centrifugation for cost effective separation of microalgae cells for biodiesel

applications. Bioresource Technology, [s.l.], v. 128, p.241-245, jan. 2013. Elsevier BV. http://dx.doi.org/10.1016/j.biortech.2012.10.0 61.

DAWOOD, Mahmoud A.o.; KOSHIO, Shunsuke. Recent advances in the role of probiotics and prebiotics in carp aquaculture: A review. Aquaculture, [s.i], v. 1, n. 254, p.243-251, 30 dez. 2015.

DECAMP, Ortho et al. Desempenho e Segurança dos Probióticos na Aquicultura. 2006. Disponível em: <http://www.panoramadaaquicultura.com.br/p aginas/revistas/97/DesempenhoeSeguranca97. asp>. Acesso em: 20 jul. 2016

DWIVEDI, Mitesh et al. Induction of regulatory T cells: A role for probiotics and prebiotics to suppress autoimmunity.Autoimmunity Reviews, [s.1.], v. 15, n. 4, p.379-392, abr. 2016. Elsevier BV. 
http://dx.doi.org/10.1016/j.autrev.2016.01.002

ELLIS, J.1. et al. The effect of lactic acid bacteria included as a probiotic or silage inoculant on in vitro rumen digestibility, total gas and methane production. Animal Feed

Science And Technology, [s.1.], v. 211, p.6174, jan. 2016. Elsevier BV.

http://dx.doi.org/10.1016/j.anifeedsci.2015.10 .016 .

EMBRAPA Recursos Genéticos e Biotecnologia. Manual de Curadores de Germoplasma - Microrganismos: Bactérias ácido-lácticas. Brasília: Embrapa, 2011. 15 p. Disponível em:

<https://www.embrapa.br/documents/135516 3/2005846/doc336-151.pdf/4c82dbc8-73bd4689-a47e-5819e3f1ffc7>. Acesso em: 14 jul. 2016.

EMBRAPA. Zoneamento Aquícola: análise de contexto e abordagens técnicas. Palmas, To: Embrapa Pesca e Aquicultura, 2015. 40 p. Disponível em:

<http://www.infoteca.cnptia.embrapa.br/infot eca/bitstream/doc/1011444/1/cnpasa2015doc 1 0.pdf>. Acesso em: 29 jun. 2016.

FADDA, Maria Elisabettaet al. In vitro screening of Kluyveromyces strains isolated from Fiore Sardo cheese for potential use as probiotics. Lwt - Food Science And Technology, [s.1.], v. 75, p.100-106, jan. 2017. Elsevier BV. http://dx.doi.org/10.1016/j.lwt.2016.08.020.

FAO (World Health Organization Food and Agriculture Organization of the United Nations). Probiotics in Food: : Health and Nutritional Properties. Fao Food And Nutritional Paper, Rome, v. 1, n. 85, p.1-56, jan. 2006. Disponível em:

<http://www.fao.org/3/a-a0512e.pdf>. Acesso em: 12 jul. 2016.

FAO. Cultured Aquatic Species Information Programme: Cyprinus carpio (Linnaeus, 1758). 2016. Disponível em: <http://www.fao.org/fishery/culturedspecies/
Cyprinus_carpio/en\#tcBioFea>. Acesso em: 01 jul. 2016.

FAO. The State of World Fisheries and Aquaculture: Opportunities and challenges. Rome: Food And Agriculture Organization Of The United Nations, 2014. 243 p.

FAZENDA, Mariana L. et al. Submerged Culture Fermentation of "Higher Fungi": The Macrofungi. Advances In Applied

Microbiology, [s.1.], p.33-103, 2008. Elsevier BV. http://dx.doi.org/10.1016/s00652164(07)00002-0.

FERNANDES, Prabhavathi; MARTENS, Evan. Antibiotics in late clinical development. Biochemical

Pharmacology, [s.1.], p.114-126, set. 2016. Elsevier BV.

http://dx.doi.org/10.1016/j.bcp.2016.09.025.

FLESCH, Aline Gamarra Taborda et al. O USO TERAPÊUTICO DOS SIMBIÓTICOS. Abcd Arq Bras Cir

Dig, Porto Alegre, v. 3, n. 1, p.206-209, maio 2014. Disponível em:

<http://www.scielo.br/pdf/abcd/v27n3/pt_010 2-6720-abcd-27-03-00206.pdf>. Acesso em: 15 jul. 2016.

FUCHS-TARLOVSKY, Vanessa; MARQUEZ-BARBA, María Fernanda; SRIRAM, Krishnan. Probiotics in dermatologic practice. Nutrition, [s.1.], v. 32, n. 3, p.289-295, mar. 2016. Elsevier BV. http://dx.doi.org/10.1016/j.nut.2015.09.001.

GONZÁLEZ-FORTE, L.; BRUNO, E.; MARTINO, M.. Application of coating on dog biscuits for extended survival of probiotic bacteria. Animal Feed Science And Technology, [s.1.], v. 195, p.76-84, set. 2014. Elsevier BV.

http://dx.doi.org/10.1016/j.anifeedsci.2014.05 .015 .

GRZEśKOWIAK, Łukasz et al. Microbiota and probiotics in canine and feline welfare. Anaerobe, [s.1.], v. 34, p.14-23, ago. 2015. Elsevier BV. 
http://dx.doi.org/10.1016/j.anaerobe.2015.04. 002.

GUO, Xia et al. Identification and characterization of Bacillus subtilis from grass carp (Ctenopharynodon idellus) for use as probiotic additives in aquatic feed. Fish \& Shellfish Immunology, Beijing, p.74-84, 15 mar. 2016.

HOD, Keren; RINGEL, Yehuda. Probiotics in functional bowel disorders. Best Practice \& Research Clinical Gastroenterology, [s.1.], v. 30, n. 1, p.89-97, fev. 2016. Elsevier BV. http://dx.doi.org/10.1016/j.bpg.2016.01.003.

JESUS, Gabriel Fernandes Alves de. Weissela cibaria e sua ação probiótica no trato intestinal de surubins híbridos.2014. 89 f. Dissertação (Mestrado) Curso de Aquicultura, Departamento de Aquicultura, Universidade Federal de Santa Catarina, Florianópolis, 2014.

KÜHLWEIN, H. et al. Effects of a dietary $\beta$ $(1,3)(1,6)$-D-glucan supplementation on intestinal microbial communities and intestinal ultrastructure of mirror carp ( Cyprinuscarpio L.). J ApplMicrobiol, [s.1.], v. 115, n. 5, p.1091-1106, 27 ago. 2013. Wiley-Blackwell. http://dx.doi.org/10.1111/jam.12313.

KUMAR, Anand et al. In vivo gut transcriptome responses to Lactobacillus rhamnosus GG and Lactobacillus acidophilus in neonatal gnotobiotic piglets. Gut

Microbes, [s.1.], v. 5, n. 2, p.152-164, 22 jan. 2014. Informa UK Limited.

http://dx.doi.org/10.4161/gmic.27877.

LAN, R.x.; KOO, J.m.; KIM, I.h.. Effects of Lactobacillus acidophilus supplementation in different energy and nutrient density diets on growth performance, nutrient digestibility, blood characteristics, fecal microbiota shedding, and fecal noxious gas emission in weaning pigs. Animal Feed Science And Technology, [s.1.], v. 219, p.181-188, set. 2016. Elsevier BV. http://dx.doi.org/10.1016/j.anifeedsci.2016.06 .018 .
MARBELIA, Lisendra et al. Polyacrylonitrile membranes for microalgae filtration:

Influence of porosity, surface charge and microalgae species on membrane fouling. Algal Research, [s.1.], v. 19, p.128137, nov. 2016. Elsevier BV. http://dx.doi.org/10.1016/j.algal.2016.08.004.

MUNIR, Mohammad Bodrul et al. Dietary prebiotics and probiotics influence growth performance, nutrient digestibility and the expression of immune regulatory genes in snakehead (Channastriata)

fingerlings. Aquaculture, [s.1.], v. 460, p.5968, jul. 2016. Elsevier BV. http://dx.doi.org/10.1016/j.aquaculture.2016.0 3.041 .

NOGUEIRA, JanaÍna CÂndida Rodrigues. Probióticos - Revisão da Literatura. Rev. Bras. Ciênc. Saúde, [s.1.], v. 15, n. 4, p.487492, 1 out. 2011. APESB (Associacao de Apoio a Pesquisa em Saude Bucal). http://dx.doi.org/10.4034/rbcs.2011.15.04.16.

NOUREDDIN, Afifa et al. Accelerated decantation of biodiesel-glycerol mixtures: Optimization of a critical stage in biodiesel biorefinery. Separation And Purification Technology, [s.1.], v. 132, p.272-280, ago. 2014. Elsevier BV. http://dx.doi.org/10.1016/j.seppur.2014.05.01 1 .

OMG - Organização Mundial de Gastroenterologia (Org.). Probióticos e Prebióticos: Guias Mundiais da WGO. Disponível em: <http://www.worldgastroenterology.org/User Files/file/guidelines/probiotics-portuguese2011.pdf>. Acesso em: 25 maio 2016.

OUWEHAND, Arthur C.; TENNILÄ, Julia. Probiotics and Antibiotic Use. Probiotics, Prebiotics, And Synbiotics, [s.1.], p.271-277, 2016. Elsevier BV. http://dx.doi.org/10.1016/b978-0-12-8021897.00018-6.

PANDIYAN, Priyadarshini et al. Probiotics in aquaculture. Drug Invention Today, [s.1.], v. 4, n. 3, p.55-59, 08 mar. 2013. 
PERRY, R. H., BENSKOW, L. R., BEIMESCH, W. E., et al. Perry's Chemical Engineers' Handbook. 8ed. Nova Iorque: McGraw-Hill, 2008.

PEYER, Lorenzo C.; ZANNINI, Emanuele; ARENDT, Elke K.. Lactic acid bacteria as sensory biomodulators for fermented cerealbased beverages. Trends In Food Science \& Technology, [s.1.], v. 54, p.17-25, ago. 2016. Elsevier BV.

http://dx.doi.org/10.1016/j.tifs.2016.05.009.

PINTO, Maria G. Vizosoet al. Lactobacillus spp. with in vitro probiotic properties from human faeces and traditional fermented products. International Journal Of Food Microbiology, Karlsruhe, v. 1, n. 109, p.2052014, 02 jan. 2006.

POHNDORF, Ricardo S. et al. Production of lipids from microalgae Spirulina sp.:

Influence of drying, cell disruption and extraction methods. Biomass And

Bioenergy, [s.1.], v. 93, p.25-32, out. 2016. Elsevier BV.

http://dx.doi.org/10.1016/j.biombioe.2016.06. 020.

REID, Gregor. Probiotics: definition, scope and mechanisms of action. Best Practice \& Research Clinical Gastroenterology, [s.1.], v. 30, n. 1, p.17-25, fev. 2016. Elsevier BV. http://dx.doi.org/10.1016/j.bpg.2015.12.001.

ROUXINOL-DIAS, Ana Lídia et al. Probiotics for the control of obesity - Its effect on weight change. Porto Biomedical

Journal, [s.1.], v. 1, n. 1, p.12-24, mar. 2016. Elsevier BV.

http://dx.doi.org/10.1016/j.pbj.2016.03.005.

SAVIJOKI, Kirsi; INGMER, Hanne; VARMANEN, Pekka. Proteolytic systems of lactic acid bacteria. Appl Microbiol

Biotechnol, [s.1.], v. 71, n. 4, p.394-406, 21 abr. 2006. Springer Science + Business Media. http://dx.doi.org/10.1007/s00253-0060427-1.

SBRT (Serviço Brasileiro de Respostas Técnicas) . Probióticos, prebióticos e simbióticos: definição, benefícios e aplicabilidade industrial. Belo Horizonte: Fundação Centro Tecnológico de Minas Gerais / Cetec, 2014. 27 p. Disponível em: $<$ http://www.respostatecnica.org.br/dossietecnico/downloadsDT/Mjc2OTU=>. Acesso em: 12 jul. 2016.

SILVA, Suse Botelho da. Produção e otimização do processo de obtenção de ácido gama-poliglutâmico através do cultivo de Bacillus subtilis BL 53. 2010. 128 f. Tese (Doutorado) - Curso de Engenharia Química, Universidade Federal do Rio Grande do Sul, Porto Alegre, 2010.

SINGH, Kamlesh et al. Probiotics: A review. Asian Pacific Journal Of Tropical Biomedicine, [s.1], v. 5, n. 8, p.287-290, 15 out. 2011.

SINGHANIA, R.R.; SUKUMARAN, R.K.; PANDEY, A. Improved cellulose production by Trichoderma reesei RUT C30 under SSF through process optimization. Applied Biochemistry and Biotechnology, v.142, p.60-70, 2007.

STOVER, Mitchel Graham; WATSON, Ronald Ross; COLLIER, Robert J..Pre- and Probiotic Supplementation in Ruminant Livestock Production. Probiotics, Prebiotics, And Synbiotics, [s.1.], p.25-36, 2016. Elsevier BV. http://dx.doi.org/10.1016/b9780-12-802189-7.00002-2.

STROMPFOVÁ, Viola et al. Effect of Bifidobacteriumanimalis B/12 administration in healthy dogs. Anaerobe, [s.1.], v. 28, p.3743, ago. 2014. Elsevier BV. http://dx.doi.org/10.1016/j.anaerobe.2014.05. 001.

TORRES, Daniel Emanoel. Avaliação dos efeitos de microrganismos probióticossobre o desempenho zootécnico, hematológico e tolerância ao estresse da truta do arco-íris (. 2014. 100 f. Dissertação (Mestrado) - Curso de Biotecnologia Industrial, Microbiologia, Universidade de São Paulo, Lorena, 2014. 
VERSCHUERE, L., Rombaut, G., Sorgeloos, P., Verstraete, W., 2000. Probiotics bacteria as biological control agents in aquaculture. Microbiol. Mol. Biol. Rew. 64, 655-671.

VLASOVA, Anastasia N. et al. Comparison of probiotic lactobacilli and bifidobacteria effects, immune responses and rotavirus vaccines and infection in different host species. Veterinary Immunology And Immunopathology, [s.1.], v. 172, p.72-84, abr. 2016. Elsevier BV.

http://dx.doi.org/10.1016/j.vetimm.2016.01.0 03.

VOHRA, Ashima; SYAL, Poonam; MADAN, Anshu. Probiotic yeasts in livestock sector. Animal Feed Science And Technology, [s.1.], v. 219, p.31-47, set. 2016. Elsevier BV.

http://dx.doi.org/10.1016/j.anifeedsci.2016.05 .019 .

VOSS, Glenise Bierhalz. Produção de Bacillus subtilis em biorreatores airlift e sua aplicação no controle de nematoide de galhas do tomateiro. 2013. $115 \mathrm{f}$.

Dissertação (Mestrado) - Curso de Engenharia de Alimentos, Universidade Federal de Santa Catarina, Florianópolis, 2013.

XU, Yi-gang et al. Probiotic properties of genetically engineered Lactobacillus plantarum producing porcine lactoferrin used as feed additive for piglets. Process

Biochemistry, [s.1.], v. 51, n. 6, p.719-724, jun. 2016. Elsevier BV.

http://dx.doi.org/10.1016/j.procbio.2016.03.0

07.

ZANCHETTA, Ariane. Produção de celulases fúngicas por fermentação em estado sólido e submersa utilizando biomassa lignocelulósica. 2012. $100 \mathrm{f}$. Dissertação (Mestrado) - Curso de Biologia, Instituto de Biociências, Letras e Ciências Exatas da Universidade Estadual Paulista “júlio de Mesquita Filho”, Unesp, São José do Rio Preto, Sp, 2012.

ZIMMERMANN, J.a. et al. Effects of probiotics in swines growth performance: A meta-analysis of randomized controlled trials.Animal Feed Science And

Technology, [s.1.], p.1-44, jun. 2016. Elsevier BV.

http://dx.doi.org/10.1016/j.anifeedsci.2016.06 .021 .

ZUPPA, Antonio Alberto et al. Prebiotics and Probiotics in Infant Nutrition. Probiotics, Prebiotics, And Synbiotics, [s.1.], p.101-134, 2016. Elsevier BV. http://dx.doi.org/10.1016/b978-0-12-8021897.00008-3. 